\title{
O papel da vitamina D na imunidade e na infecção por coronavírus: Uma revisão da
}

\section{literatura}

The role of vitamin D in immunity and coronavirus infection: A literature review

El papel de la vitamina $D$ en la inmunidad y la infección por coronavirus: Una revisión de la literatura

Gleicy Kelly China Quemel

ORCID: https://orcid.org/0000-0003-1280-560X Escola Superior da Amazônia, Brasil

E-mail: gkcquemel@gmail.com

Marinalva Tavares Sozinho

ORCID: https://orcid.org/0000-0003-4049-8918

Escola Superior da Amazônia, Brasil

E-mail: cordejambo28@gmail.com

José Alberto Paiva da Costa

ORCID: https://orcid.org/0000-0003-2190-3463

Escola Superior da Amazônia, Brasil

E-mail: j.albertocosta123@gmail.com

Cibelly Lima Marinho

ORCID: https://orcid.org/0000-0001-7141-9667

Escola Superior da Amazônia, Brasil

E-mail: limacibelly@gmail.com

Glenda Keyla China Quemel

ORCID: https://orcid.org/0000-0002-9696-3447

Universidade do Estado do Pará, Brasil

E-mail: glenda.quemel@gmail.com

Danilo Reymão Moreira

ORCID: https://orcid.org/0000-0003-0381-5064

Escola Superior da Amazônia, Brasil

E-mail: alydan@hotmail.com

Gabriel Cardoso de Queiroz Santos

ORCID: https://orcid.org/0000-0002-9530-4845

Escola Superior da Amazônia, Brasil

E-mail: gabrieldequeirozsantos@gmail.com

\begin{abstract}
Resumo
A vitamina D (VD) é um pré-hormônio e desempenha várias funções: regulador do desenvolvimento ósseo, apresenta atividades antivirais, antifibrótica, imunomoduladora, e de acordo com estudos pode ser capaz de reduzir o risco de morte na infecção por coronavírus, vírus que foi identificado primeiramente em Wuhan (China) em dezembro de 2019 e espalhou-se rapidamente pelo mundo. Dessa forma, o objetivo desta revisão integrativa é conhecer o que a literatura mundial tem publicado acerca da importância clínica da VD na prevenção da infecção por coronavírus. Para a busca dos artigos foram utilizados os descritores, contidos nos DeCs,: [vitamina D/Vitamin D ], [imunidade/ immunity] e [infecção por coronavírus/ coronavirus infections], consultados na base de dados Medline. Os critérios de inclusão foram: artigos completos, disponíveis nos idiomas português e inglês publicados entre 2011 a 04/2021. Foram selecionados trinta artigos no idioma inglês, em que cerca de 36,4\% (11) discorrem sobre os fatores que influenciam os níveis séricos da VD organismo e suas implicações na infecção por coronavírus, e 63,3\% (19) abordam os mecanismos de ação da VD no sistema imunológico em relação à infecção por coronavírus. Sabe-se que a VD modula a função de células imunes, em uma interação sistema imune inato-adaptativo, regula a expressão e secreção de citocinas, portanto, a intervenção terapêutica com VD pode prevenir e tratar essa doença, impedindo que casos leves se tornem graves. Portanto, a suplementação seria a ferramenta terapêutica efetiva para contrapor a deficiência de VD, mas são necessários mais estudos clínicos para efetivamente comprovar a sua eficácia.
\end{abstract}

Palavras-chave: Vitamina D; Funções e importância clínica; Imunidade; Infecção por coronavírus.

\begin{abstract}
Vitamin D (DV) is a pre-hormone and performs several functions: regulator of bone development, has antiviral, antifibrotic, immunomodulatory activities, and according to studies it may be able to reduce the risk of death from coronavirus infection, virus that was first identified in Wuhan (China) in December 2019 and spread rapidly around the world. Thus, the objective of this integrative review is to know what the world literature has published about the
\end{abstract}


clinical importance of RV in preventing coronavirus infection. To search for the articles, the descriptors contained in the DeCs were used: [vitamin D / Vitamin D], [immunity / immunity] and [coronavirus infection / coronavirus infections], consulted in the Medline database. The inclusion criteria were: complete articles, available in Portuguese and English, published between 2011 and 04/2021. Thirty articles were selected in the English language, in which about $36.4 \%$ (11) discuss the factors that influence the serum levels of the RV organism and its implications for coronavirus infection, and $63.3 \%$ (19) address the mechanisms of action of the RV in the immune system in relation to coronavirus infection. It is known that the VD modulates the function of immune cells, in an innate-adaptive immune system interaction, regulates the expression and secretion of cytokines, therefore, the therapeutic intervention with VD can prevent and treat this disease, preventing mild cases from becoming serious. Therefore, supplementation would be the effective therapeutic tool to counter RV deficiency, but further clinical studies are needed to effectively prove its effectiveness.

Keywords: Vitamin D; Functions and clinical importance; Immunity; Coronavirus infection.

\section{Resumen}

La vitamina D (DV) es una prehormonal y realiza varias funciones: regulador del desarrollo óseo, tiene actividades antivirales, antifibróticas, inmunomoduladoras y, según estudios, puede reducir el riesgo de muerte por infección por coronavirus, virus que se identificó por primera vez en Wuhan (China) en diciembre de 2019 y se extendió rápidamente por todo el mundo. Así, el objetivo de esta revisión integradora es conocer lo que la literatura mundial ha publicado sobre la importancia clínica del RV en la prevención de la infección por coronavirus. Para la búsqueda de los artículos se utilizaron los descriptores contenidos en las DeC: [vitamina D / Vitamina D], [inmunidad / inmunidad] e [infección por coronavirus / infecciones por coronavirus], consultados en la base de datos de Medline. Los criterios de inclusión fueron: artículos completos, disponibles en portugués e inglés, publicados entre 2011 y 20/0421. Se seleccionaron 30 artículos en idioma inglés, en los que alrededor del 36,4\% (11) discuten los factores que influyen en los niveles séricos del organismo del RV y sus implicaciones para la infección por coronavirus, y el 63,3\% (19) abordan los mecanismos de acción del RV en el sistema inmunológico en relación con la infección por coronavirus. Se sabe que la VD modula la función de las células inmunes, en una interacción innata-sistema inmune adaptativo, regula la expresión y secreción de citocinas, por tanto, la intervención terapéutica con la VD puede prevenir y tratar esta enfermedad, evitando que los casos leves se agraven. . Por lo tanto, la suplementación sería la herramienta terapéutica eficaz para contrarrestar la deficiencia de RV, pero se necesitan más estudios clínicos para probar eficazmente su eficacia.

Palabras clave: Vitamina D; Funciones e importancia clínica; Inmunidad; Infección por coronavirus.

\section{Introdução}

Segundo a Organização Pan-Americana de Saúde (OPAS), COVID-19 é uma doença infecciosa causada pelo novo coronavírus, identificado pela primeira vez em Wuhan (China) em 2019. O SARS-CoV-2 detém genoma de RNA de fita simples de sentido positivo pertencente ao gênero Betacoronavírus, possui elevada transmissibilidade e apresenta sintomatologia como febre, mal-estar, tosse seca, dispneia e em casos mais severos pneumonia, podendo provocar a morte (Chan et al., 2020).

A Organização Mundial da Saúde (OMS), caracterizou em 11 de março de 2020, o surto dessa doença como uma pandemia, com graves consequências à curto e longo prazo para os indivíduos, sistemas de saúde e economias (Siuka, Pfeifer \& Pinter, 2020). Atualmente, o tratamento dá-se por meio do uso de vacinas licenciadas pelos órgãos reguladores (Rawatt, Kumari \& Saha, 2021). Outra forma de tratamento preventivo e/ou adjuvante seria o uso de vitamina D (VD), diversos estudos fornecem evidências de que essa vitamina pode ser útil na redução do risco associado às mortes por COVID19 (Moozhipurath, Kraft \& Skiera, 2020).

A vitamina D (VD) é um pré-hormônio esteróide envolvido em diversos processos físiológicos como homeostase do cálcio, fosfato, ferro, zinco, entre outros, por meio de sua ligação ao receptor da VD (VDR). As principais formas de VD são: ergocalciferol (VD2) proveniente de fontes alimentares, como vegetais, fungos e leveduras e colecalciferol (VD3), sintetizada na pele por meio de reação fotoquímica (Ferrari et al., 2017). Em virtude das diversas funções metabólicas que desempenha no organismo, a VD pode contribuir positivamente para o fortalecimento do sistema imunológico, atenuando a progressão e melhorando o prognóstico dos pacientes (Bouillon et al., 2019). Nesse contexto, faz-se necessário investigar qual é o papel da vitamina D na imunidade e como ela atua na infecção por coronavírus? 
De acordo com estudos recentes, a deficiência de VD é um importante fator etiológico na patogênese de muitas doenças crônicas e infecções (como infecções do trato respiratório superior) (Gröber, Reichrath \& Holick , 2015). Em razão disso, a deficiência ou insuficiência global de VD é uma grande preocupação para a saúde pública. Portanto, o trabalho tem como objetivo, conhecer o que a literatura mundial tem publicado acerca da importância clínica da VD na prevenção da infecção por coronavírus, a fim de analisar quais fatores influenciam os níveis séricos da VD no organismo e suas implicações nessa infecção, e os possíveis mecanismos de ação no sistema imunológico em relação à infecção por COVID-19.

\section{Metodologia}

O estudo se qualifica como uma revisão integrativa da literatura (RIL), que fornece uma compreensão mais ampla do assunto estudado, pois é uma metodologia que proporciona uma síntese de conhecimento que faz uma abrangente abordagem metodológica sobre o conhecimento atual a respeito de temática específica (Souza, Silva \& Carvalho, 2010). A pergunta que norteou o trabalho foi: "Qual é o papel da vitamina D na imunidade e como atua na infecção por coronavírus?"

Para a busca de fontes primárias foram utilizados os descritores, contidos nos descritores em ciência da saúde (DeCs): [vitamina D /Vitamin D], [imunidade/immunity] e [infecção por coronavirus/coronavirus infections], os quais foram utilizados isoladamente ou em associação para refinar a busca juntamente com o operador booleano "AND".

Foi utilizada a base de dados Medline (Medical Literature Analysis and Retrievel System Online) e a biblioteca do Scielo (Scientific Electronic Library Online). Os critérios de inclusão utilizados forma: artigos completos, disponíveis na íntegra e publicados nos últimos dez anos (2011 à 04/2021), nos idiomas português e inglês; e exclusos artigos duplicados e com acesso restrito a pagamento.

Neste estudo científico, os artigos foram submetidos à análise de conteúdo de Bardin (2011), que apresenta três fases: na pré-análise foram utilizados cinco filtros em conformidade com os critérios de inclusão e exclusão; na exploração do material, são as etapas de codificação do material selecionado, nessa fase foi realizado o recorte das unidades de registro e a categorização em eixos temáticos, conforme demonstrado no Quadro 1; o tratamento dos resultados, consistiu em relacionar os dados obtidos com a fundamentação teórica, com intuito de fazer a inferência e interpretação dos resultados. Neste estudo, essa interpretação foi constituída nos seguintes passos: apresentação dos estudos selecionados e explanação dos eixos temáticos.

Quadro 1: Unidades de registro e eixos temáticos.

\begin{tabular}{|c|c|}
\hline UNIDADE DE REGISTRO & EIXOS TEMÁTICOS \\
\hline Níveis séricos & \\
\cline { 1 - 1 } Mecanismo de ação & \\
\hline Sistema imunológico & \\
\hline Vitamina D na prevenção & SARS-Cov-2 \\
\hline
\end{tabular}

Fonte: Autores (2021).

\section{Resultados e Discussão}

A pesquisa por fontes primárias foram realizadas no banco de dados MEDLINE, todos os estudos, $100 \%$ (30 artigos), em versão completa, gratuita e no idioma inglês. Dos 30 artigos selecionados, 98 \% (29) são revisões da literatura, distribuídas em revisões integrativas (25 artigos), revisões sistemáticas (2 artigos) e narrativas (2 artigos), e 1\% (1) estudo retrospectivo.

Com relação aos conteúdos abordados nas fontes primárias, cerca de 36,4\% (11 artigos) discorrem sobre os fatores que influenciam os níveis séricos da Vitamina D no organismo e suas implicações na infecção por coronavírus e 63,3\% (19) abordam os mecanismo de ação da Vitamina D no sistema imunológico em relação à infecção por coronavírus. 
No Quadro 2 é possível observar o detalhamento dos estudos selecionados, informando autor/ano/título, abordagem metodológica, objetivo e conclusão

Quadro 2: Detalhamento dos estudos.

\begin{tabular}{|c|c|c|c|c|c|}
\hline $\mathbf{N}^{\circ}$ & Fonte Primária & Autor/Ano & Abordagem Metodológica & Objetivo & Conclusão \\
\hline 01 & $\begin{array}{l}\text { Treatment and } \\
\text { prevention of vitamin } \\
\text { D deficiency: a clinical } \\
\text { practice guideline from } \\
\text { the Endocrine Society }\end{array}$ & $\begin{array}{l}\text { Holick, Binkley } \\
\text { \& Bischoff- } \\
\text { Ferrari } \\
\text { (2011) }\end{array}$ & $\begin{array}{l}\text { Revisão sistemática de } \\
\text { evidências e discussão por } \\
\text { teleconferências. }\end{array}$ & $\begin{array}{l}\text { Fornecer orientações aos } \\
\text { médicos para avaliação, } \\
\text { tratamento e prevenção da } \\
\text { deficiência de VD. }\end{array}$ & $\begin{array}{l}\text { Recomenda-se a suplementação } \\
\text { de VD, mediante avaliação das } \\
\text { circunstâncias clínicas. }\end{array}$ \\
\hline 02 & $\begin{array}{l}\text { Vitamin } D \text { and the } \\
\text { immune system }\end{array}$ & $\begin{array}{l}\text { Aranow, } \\
(2011)\end{array}$ & $\begin{array}{l}\text { Revisão Integrativa sobre } \\
\text { os Efeitos da VD na função } \\
\text { imunológica e } \\
\text { de Veficiência } \\
\text { autoimunes. }\end{array}$ & $\begin{array}{l}\text { Compreender os efeitos da } \\
\text { VD nas células do sistema } \\
\text { imunológico; Evidenciar as } \\
\text { implicações da deficiência } \\
\text { de VD no sistema } \\
\text { imunológico e a ligação da } \\
\text { deficiência de VD e } \\
\text { doenças autoimunes. }\end{array}$ & $\begin{array}{l}\text { As células do sistema } \\
\text { imunológico são capazes de } \\
\text { sintetizar e responder à VD. Em } \\
\text { doenças autoimunes são } \\
\text { responsivas aos efeitos } \\
\text { melhoradores da VD, podendo se } \\
\text { estender além dos efeitos nos } \\
\text { ossos e homeostase do cálcio. }\end{array}$ \\
\hline 03 & $\begin{array}{l}\text { The non-skeletal } \\
\text { effects of vitamin D: A } \\
\text { scientific statement } \\
\text { from the endocrine } \\
\text { society }\end{array}$ & $\begin{array}{l}\text { Rosen et al., } \\
\quad(2012)\end{array}$ & $\begin{array}{l}\text { Revisão Sistemática dos } \\
\text { aspectos básicos e clínicos } \\
\text { da VD em relação aos } \\
\text { sistemas de órgãos não } \\
\text { esqueléticos. }\end{array}$ & $\begin{array}{l}\text { Demonstrar que o receptor } \\
\text { da VD é expresso em todas } \\
\text { as células do corpo e que } \\
\text { crescentes dados sustentam } \\
\text { uma relação da 25- } \\
\text { hidroxivitamina D sérica } \\
\text { com doenças metabólicas, } \\
\text { cardiovasculares } \\
\text { neoplásicas crônicas. }\end{array}$ & $\begin{array}{l}\text { Nesta Declaração Científica, } \\
\text { delineou-se evidências que } \\
\text { definem os efeitos da VD nos } \\
\text { tecidos epidérmico, } \\
\text { neuromuscular, cardiovascular } \\
(\mathrm{CV}) \text {, metabólico, imunológico, } \\
\text { materno/fetal e neoplásico, } \\
\text { mediante o receptor VDR, } \\
\text { através do qual a VD atua nos } \\
\text { tecidos não-esqueléticos. }\end{array}$ \\
\hline 04 & $\begin{array}{l}\text { The implication of } \\
\text { vitamin D and } \\
\text { autoimmunity: a } \\
\text { comprehensive review }\end{array}$ & $\begin{array}{l}\text { Yang, Leung } \\
\text { Adamopoulos \& } \\
\text { Gershwin } \\
\text { (2013) }\end{array}$ & $\begin{array}{l}\text { Revisão Integrativa sobre a } \\
\text { descoberta do receptor da } \\
\text { VD em múltiplas linhagens } \\
\text { de células imunes. }\end{array}$ & $\begin{array}{l}\text { Discutir a descoberta do } \\
\text { receptor da VD em } \\
\text { múltiplas linhagens de } \\
\text { células imunes; } \\
\text { Investigar o papel da VD } \\
\text { na modulação das funções } \\
\text { imunológicas e no } \\
\text { desenvolvimento } \\
\text { prevenção de doenças } \\
\text { autoimunes. }\end{array}$ & $\begin{array}{l}\text { Devido à alta prevalência de } \\
\text { insuficiência / deficiência de VD } \\
\text { em pacientes com Esclerose } \\
\text { Múltipla (EM), Diabetes tipo } 1 \\
\text { (DM1) e Lúpus Erimatoso } \\
\text { Sistêmico (LES), a } \\
\text { suplementação de VD tem sido } \\
\text { considerada para o tratamento de } \\
\text { tais doenças autoimunes. }\end{array}$ \\
\hline 05 & Vitamin D and aging & $\begin{array}{l}\text { Galagher, } \\
\text { (2013) }\end{array}$ & $\begin{array}{l}\text { Revisão Integrativa sobre o } \\
\text { Metabolismo da VD, } \\
\text { envelhecimento, } \\
\text { insuficiência de VD, } \\
\text { tratamento de idosos com } \\
\text { VD. }\end{array}$ & $\begin{array}{l}\text { Analisar os efeitos da idade } \\
\text { sobre o metabolismo da } \\
\text { VD e do cálcio. }\end{array}$ & $\begin{array}{l}\text { As mudanças relacionadas à } \\
\text { idade afetam o metabolismo da } \\
\text { VD e reduzem o estado } \\
\text { nutricional dos idosos, por isso, } \\
\text { recomenda-se fazer } \\
\text { suplementação desta vitamina, } \\
\text { no entanto, aumentar o cálcio de } \\
\text { fontes dietéticas pode ser mais } \\
\text { seguro do que suplementos. }\end{array}$ \\
\hline 06 & $\begin{array}{l}\text { Vitamin D and immune } \\
\text { function }\end{array}$ & $\begin{array}{l}\text { Prietl et al., } \\
\text { (2013) }\end{array}$ & $\begin{array}{l}\text { Revisão Integrativa sobre } \\
\text { os efeitos da VD no } \\
\text { sistema imunológico em } \\
\text { geral, na regulação das } \\
\text { respostas inflamatórias e } \\
\text { nos mecanismos } \\
\text { regulatórios ligados a } \\
\text { doenças autoimunes, } \\
\text { particularmente no } \\
\text { diabetes mellitus tipo } 1 .\end{array}$ & $\begin{array}{l}\text { Fornecer um resumo geral } \\
\text { da VD e seus efeitos no } \\
\text { sistema imunológico inato } \\
\text { e adaptativo com foco em } \\
\text { doenças autoimunes, } \\
\text { particularmente, aos } \\
\text { avanços recentes em T1D e } \\
\text { MS. }\end{array}$ & $\begin{array}{l}\text { Nas últimas décadas, a pesquisa } \\
\text { da VD confirmou importantes } \\
\text { interações entre a VD e as } \\
\text { células do sistema imunológico } \\
\text { inato e adaptativo. Dessa forma, } \\
\text { a VD surge como um nutriente } \\
\text { promissor e relativamente seguro } \\
\text { para novas estratégias na } \\
\text { prevenção e tratamento auxiliar } \\
\text { de doenças causadas por } \\
\text { comprometimento } \\
\text { homeostase imunológica. }\end{array}$ \\
\hline 07 & Vitamin D metabolism, & Bikle, (2014) & Revisão integrativa sobre & Compreender os aspectos & A VD é um hormônio esteróide \\
\hline
\end{tabular}




\begin{tabular}{|c|c|c|c|c|c|}
\hline & $\begin{array}{lr}\text { mechanism of action } \\
\text { and } & \text { clinical } \\
\text { applications } & \end{array}$ & & $\begin{array}{l}\text { os diferentes aspectos do } \\
\text { metabolismo da VD, } \\
\text { mecanismo de ação e } \\
\text { aplicação clínica. }\end{array}$ & $\begin{array}{l}\text { do metabolismo da VD e os } \\
\text { mecanismos de ação que } \\
\text { podem ser manipulados } \\
\text { para facilitar as aplicações } \\
\text { clínicas específicas do } \\
\text { tecido. }\end{array}$ & $\begin{array}{l}\text { que se liga ao seu receptor } \\
\text { VDR. Dada a ampla expressão } \\
\text { de VDR e CYP27B1, há grande } \\
\text { interesse em identificar meios de } \\
\text { direcionar células específicas } \\
\text { com análogos que não aumentem } \\
\text { a absorção intestinal de cálcio } \\
\text { e/ou reabsorção óssea, para } \\
\text { tratamento / prevenção de } \\
\text { câncer, doença cardiovascular } \\
\text { (DCV) e infeç̧ões virais. }\end{array}$ \\
\hline 08 & $\begin{array}{l}\text { The medico-legal } \\
\text { aspects of the } \\
\text { prescription of vitamin } \\
\text { D }\end{array}$ & $\begin{array}{l}\text { Davies, Poole \& } \\
\text { Feldschreiber, } \\
\text { (2014) }\end{array}$ & $\begin{array}{l}\text { Revisão Integrativa sobre } \\
\text { Prescrição licenciada e } \\
\text { não-licenciada de VD; } \\
\text { parâmetros médico-legais; } \\
\text { Segurança e toxicidade de } \\
\text { VD. }\end{array}$ & $\begin{array}{l}\text { Abordar as questões } \\
\text { relacionadas ao uso clínico } \\
\text { de produtos de VD não } \\
\text { licenciados, questões de } \\
\text { segurança que podem } \\
\text { surgir a partir disso; } \\
\text { discutir as } \\
\text { responsabilidades médico- } \\
\text { legais do prescritor e } \\
\text { dispensador. }\end{array}$ & $\begin{array}{l}\text { Na última década houve um } \\
\text { renascimento do interesse e uma } \\
\text { expansão na prescrição de VD. } \\
\text { Os prescritores e dispensadores } \\
\text { precisam avaliar os perigos } \\
\text { potenciais para seus pacientes e } \\
\text { também o risco para seu status } \\
\text { profissional associado ao uso de } \\
\text { produtos de VD não licenciados. }\end{array}$ \\
\hline 09 & $\begin{array}{l}\text { Live longer with } \\
\text { Vitamin D? }\end{array}$ & $\begin{array}{l}\text { Gröber, } \\
\text { Reichrath \& } \\
\text { Holick } \\
(2015)\end{array}$ & $\begin{array}{l}\text { Revisão Integrativa a partir } \\
\text { de discussão de uma meta- } \\
\text { análise sobre os baixos } \\
\text { níveis de } 25 \text { (OH) D } \\
\text { associados ao aumento } \\
\text { significativo do risco de } \\
\text { mortalidade por todas as } \\
\text { causas. }\end{array}$ & $\begin{array}{l}\text { Entender quais dos } \\
\text { processos são mediados } \\
\text { apenas por UV e quais são } \\
\text { via VD e Se há ou não uma } \\
\text { conexão entre o status da } \\
\text { VD e a mortalidade geral. }\end{array}$ & $\begin{array}{l}\text { Mais atenção deve ser dada à } \\
\text { deficiência de VD na prática } \\
\text { médica e farmacêutica. Os dados } \\
\text { disponíveis até o momento em } \\
\text { vários estudos sobre a VD são } \\
\text { significativos e confirmam o } \\
\text { papel essencial da vitamina do } \\
\text { sol em uma variedade de funções } \\
\text { fisiológicas e preventivas. }\end{array}$ \\
\hline 10 & $\begin{array}{l}\text { Vitamin } \\
\text { metabolism, molecular } \\
\text { mechanism of action } \\
\text { and pleiotropic effects }\end{array}$ & $\begin{array}{l}\text { Christakos et } \\
\text { al., (2015) }\end{array}$ & $\begin{array}{l}\text { Revisão } \\
\text { Integrativa sobre a } \\
\text { compreensão atual da VD, } \\
\text { sua bioativação e novos } \\
\text { desenvolvimentos que } \\
\text { mudaram a compreensão } \\
\text { de seu mecanismo de ação } \\
\text { em tecidos-alvo clássicos e } \\
\text { não clássicos. }\end{array}$ & $\begin{array}{l}\text { Avaliar o papel da VD na } \\
\text { saúde extraesquelético; } \\
\text { Fornecer uma visão geral } \\
\text { de } 1,25(\mathrm{OH}) 2 \mathrm{D} 3 \text { análogos } \\
\text { que têm r sido } \\
\text { desenvolvidos; Indicar } \\
\text { questões que permanecem e } \\
\text { precisam ser abordadas. }\end{array}$ & $\begin{array}{l}\text { Embora as redes globais } \\
\text { reguladas por VDR estejam } \\
\text { começando a ser abordadas nas } \\
\text { células imunológicas, são } \\
\text { necessários mais estudos } \\
\text { relacionados a todo o genoma, } \\
\text { proteoma e análises metabólicas } \\
\text { para definir os múltiplos papéis } \\
\text { da VD na função imunológica. }\end{array}$ \\
\hline 11 & $\begin{array}{l}\text { Vitamin D and } \\
\text { infectious diseases: } \\
\text { Simple observer or } \\
\text { contributing factor? }\end{array}$ & $\begin{array}{l}\text { Gois et al., } \\
\text { (2017) }\end{array}$ & $\begin{array}{l}\text { Revisão Integrativa sobre a } \\
\text { Avaliação } \\
\text { suplementação de VD em } \\
\text { doenças infecciosas, como } \\
\text { tuberculose } \\
\text { infecções do tra), } \\
\text { respiratório (RTIs), vírus } \\
\text { da imunodeficiência } \\
\text { humana (HIV), infecções } \\
\text { fúngicas e septicemia. }\end{array}$ & $\begin{array}{l}\text { Discutir o papel da VD na } \\
\text { modulação do sistema } \\
\text { imunológico e a relação } \\
\text { entre o estado de VD e } \\
\text { várias doenças infecciosas, } \\
\text { como TB, RTIs, HIV, } \\
\text { infecções fúngicas e } \\
\text { septicemia. } \\
\text { criticamente as evidências } \\
\text { mais recentes sobre o } \\
\text { monitoramento e a } \\
\text { suplementação de VD no } \\
\text { contexto de doenças } \\
\text { infecciosas. }\end{array}$ & $\begin{array}{l}\text { Em resumo, os estudos revisados } \\
\text { destacam o importante papel da } \\
\text { VD, uma vez que, o VDD } \\
\text { (Deficiência de VD) pode de fato } \\
\text { contribuir para a patogênese de } \\
\text { várias doenças infecciosas ao } \\
\text { modular negativamente os } \\
\text { processos vitais, como a resposta } \\
\text { imune inata e adaptativa. }\end{array}$ \\
\hline 12 & $\begin{array}{l}\text { Oral calcidiol is a good } \\
\text { form of vitamin D } \\
\text { supplementation }\end{array}$ & $\begin{array}{l}\text { Biondi et al., } \\
\text { (2017) }\end{array}$ & \begin{tabular}{lr}
\multicolumn{2}{l}{ Revisão Integrativa a partir } \\
de análise de & Estudos \\
multicêntrico & $\mathrm{e}$ \\
randomizado & sobre \\
suplementação & de \\
Calcidiol oral. &
\end{tabular} & $\begin{array}{l}\text { Analisar a importância da } \\
\text { suplementação de VD no } \\
\text { manejo clínico dos estados } \\
\text { de deficiência, } \\
\text { principalmente no que se } \\
\text { refere à forma, doses e } \\
\text { esquema de doses a serem } \\
\text { utilizados e as vantagens do } \\
\text { uso do calcidiol. }\end{array}$ & $\begin{array}{l}\text { Em conclusão, o calcidiol } \\
\text { demonstrou ser eficaz na } \\
\text { melhora rápida e segura do status } \\
\text { de VD e na manutenção de } \\
\text { níveis séricos adequados de VD } \\
\text { com efeito positivo nos órgãos- } \\
\text { alvo da VD. }\end{array}$ \\
\hline
\end{tabular}




\begin{tabular}{|c|c|c|c|c|c|}
\hline 13 & $\begin{array}{l}\text { Regarding the vitamin } \\
\text { D reference range: Pre- } \\
\text { analytical and } \\
\text { analytical variability of } \\
\text { vitamin } \\
\text { measurement }\end{array}$ & $\begin{array}{c}\text { Ferrari, } \\
\text { Lombardi, \& } \\
\text { Banfi (2017) }\end{array}$ & $\begin{array}{l}\text { Revisão Integrativa a partir } \\
\text { de Estudos dos principais } \\
\text { fatores que influenciam a } \\
\text { variabilidade r das } \\
\text { concentrações de VD } \\
\text { utilizando uma curva de } \\
\text { percentis, } \\
\text { individualmente ralculada } \\
\text { avaliar as concentrações } \\
\text { anormais de VD em } \\
\text { indivíduos saudáveis. }\end{array}$ & $\begin{array}{l}\text { Discutir os fatores } \\
\text { ambientais, genéticos e } \\
\text { instrumentais que podem } \\
\text { influenciar } \\
\text { concentrações medidas de } \\
25(\mathrm{OH}) \mathrm{D} \text { total; } \\
\text { Averiguar se uma faixa } \\
\text { variável pode ser mais } \\
\text { adequada do que um limite } \\
\text { fixo para avaliar as } \\
\text { concentrações anormais de } \\
\text { VD. }\end{array}$ & $\begin{array}{l}\text { A prevalência de deficiência } \\
\text { /insuficiência de VD é alta e } \\
\text { pode aumentar } \\
\text { futuro. Portanto, é desejável } \\
\text { incluir a avaliação da VD no } \\
\text { exame de rotina para monitorar } \\
\text { suas concentrações e } \\
\text { acompanhar eventuais regimes } \\
\text { de suplementação. }\end{array}$ \\
\hline 14 & $\begin{array}{l}\text { Vitamin D: nutrient, } \\
\text { hormone } \\
\text { immunomodulator }\end{array}$ & $\begin{array}{l}\text { Sassi , Tamone } \\
\text { \& D'Amelio } \\
\text { (2018) }\end{array}$ & $\begin{array}{l}\text { Revisão Integrativa a partir } \\
\text { do resumo de dados } \\
\text { experimentais } \\
\text { observações clínicas sobre } \\
\text { as propriedades } \\
\text { imunomoduladoras } \\
\text { potenciais da VD. }\end{array}$ & $\begin{array}{l}\text { Investigar o papel da VD } \\
\text { na regulação do sistema } \\
\text { imunológico com foco na } \\
\text { experiência dos autores na } \\
\text { exploração de evidências } \\
\text { recentes nos campos } \\
\text { experimental e clínico. }\end{array}$ & $\begin{array}{l}\text { Em resumo, vários estudos } \\
\text { apontam para o importante papel } \\
\text { da VD como um } \\
\text { imunomodulador, e dados } \\
\text { sólidos demonstram que a } 1,25 \\
\text { (OH)2D3 aumenta a capacidade } \\
\text { de luta do sistema imunológico } \\
\text { inato contra patógenos, enquanto } \\
\text { dados sobre o efeito da } 1,25 \\
\text { (OH)2 D3 na modulação do } \\
\text { sistema imunológico adquirido } \\
\text { ainda é controverso. }\end{array}$ \\
\hline 15 & $\begin{array}{l}\text { Self-care for common } \\
\text { colds: the central role } \\
\text { of vitamin D, vitamin } \\
\mathrm{C} \text {, zinc and echinacea } \\
\text { in three main immune } \\
\text { systems interactive } \\
\text { groups (physical } \\
\text { barriers, innate and } \\
\text { adaptive immunity) } \\
\text { involved during an } \\
\text { episode of common } \\
\text { colds practical dosage } \\
\text { advice and time to take } \\
\text { these nutrients / } \\
\text { botanicals to prevent or } \\
\text { treat common colds }\end{array}$ & $\begin{array}{l}\text { Rondanelli et } \\
\text { al., (2018) }\end{array}$ & $\begin{array}{l}\text { Revisão Narrativa a partir } \\
\text { de } 82 \text { estudos elegíveis que } \\
\text { consideram o papel } \\
\text { preventivo } \\
\text { nutrientes em } r \text { desses } \\
\text { imunológicos e em CC } \\
\text { para fornecer conselhos } \\
\text { sobre a dosagem e tempo } \\
\text { de ingestão desses } \\
\text { nutrientes. }\end{array}$ & $\begin{array}{l}\text { Considerar o papel central } \\
\text { da VD, vitamina C, zinco } \\
\text { e equinácea em três grupos } \\
\text { interativos imunológicos } \\
\text { principais (barreiras físicas, } \\
\text { imunidade inata e } \\
\text { adaptativa) em termos de } \\
\text { prevenção e tratamento } \\
\text { (encurtamento a duração e / } \\
\text { ou diminuição da gravidade } \\
\text { dos sintomas) de resfriados } \\
\text { comuns, a fim de fornecer } \\
\text { conselhos práticos sobre as } \\
\text { dosagens e sobre o tempo } \\
\text { de ingestão desses } \\
\text { nutrientes. }\end{array}$ & $\begin{array}{l}\text { Em conclusão, a evidência atual } \\
\text { de eficácia para zinco, vitaminas } \\
\mathrm{D} \text { e C e equinácea é tão } \\
\text { interessante que os pacientes } \\
\text { com CC podem ser encorajados } \\
\text { a experimentá-los para prevenir / } \\
\text { tratar seus resfriados, embora } \\
\text { mais estudos sejam necessários } \\
\text { sobre esse assunto. }\end{array}$ \\
\hline 16 & $\begin{array}{l}\text { A study of vitamin D: a } \\
16 \text {-year retrospective } \\
\text { study at an academic } \\
\text { medical center }\end{array}$ & $\begin{array}{l}\text { Lee et al., } \\
\text { (2018) }\end{array}$ & $\begin{array}{l}\text { Estudo retrospectivo em } \\
\text { humanos a partir da } \\
\text { Investigação retrospectiva } \\
\text { dos níveis séricos elevados } \\
\text { de } 25(\mathrm{OH}) \mathrm{D} \text { durante o } \\
\text { período de } 16 \text { anos } \\
\text { na University of Iowa } \\
\text { Hospitals and Clinics } \\
\text { (UIHC). }\end{array}$ & 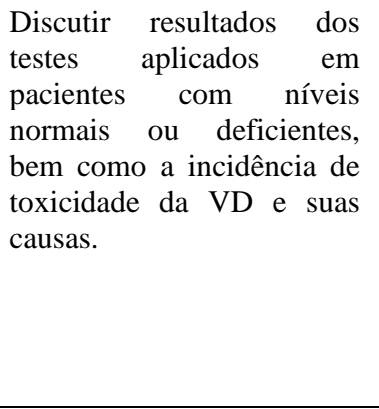 & $\begin{array}{l}\text { A toxicidade sintomática da VD } \\
\text { é bastante rara e os níveis } \\
\text { elevados não se correlacionam } \\
\text { fortemente com os sintomas } \\
\text { clínicos ou com os níveis } \\
\text { séricos/plasmáticos totais de } \\
\text { cálcio. No entanto, mais estudos } \\
\text { são necessários em relação às } \\
\text { diretrizes de suplementação de } \\
\text { VD e definições de toxicidade da } \\
\text { VD. }\end{array}$ \\
\hline 17 & $\begin{array}{l}\text { Vitamin D deficiency } \\
\text { and supplementation in } \\
\text { critical illnesses - } \\
\text { known and unknown } \\
\text { acquaintances }\end{array}$ & $\begin{array}{l}\text { Nair, Venkatesh } \\
\& \text { Center (2018) }\end{array}$ & $\begin{array}{l}\text { Revisão Integrativa a partir } \\
\text { de Análise dos artigos } \\
\text { pertinentes ao estudo. }\end{array}$ & $\begin{array}{l}\text { Analisar dados atuais } \\
\text { relacionados com o déficit } \\
\text { de VD e doenças criticas e } \\
\text { os possíveis benefícios } \\
\text { clínicos da VD não } \\
\text { elucidados. }\end{array}$ & $\begin{array}{l}\text { Foram observados benefícios } \\
\text { adicionais em vários órgãos, } \\
\text { porém, estudos randomizados } \\
\text { são necessários para dar respaldo } \\
\text { as pesquisas. }\end{array}$ \\
\hline 18 & $\begin{array}{l}\text { Vitamin D and flu - } \\
\text { prevention or therapy? }\end{array}$ & $\begin{array}{l}\text { Gruber-Bizura, } \\
\qquad(2018)\end{array}$ & $\begin{array}{l}\text { Revisão Integrativa a partir } \\
\text { da Análise de diversos } \\
\text { estudos ("in vitro", "in } \\
\text { vivo" e Randomizado) a } \\
\text { respeito da associação } \\
\text { entre a resposta imune e a } \\
\text { concentração sérica de VD. }\end{array}$ & $\begin{array}{l}\text { Apresentar dados recentes } \\
\text { sobre o possível papel da } \\
\text { VD na modulação da } \\
\text { resposta imune na infecção } \\
\text { pelo vírus da influenza. }\end{array}$ & $\begin{array}{l}\text { Os estudos mostram claramente } \\
\text { que a VD é, sem dúvida, parte } \\
\text { importante para equilíbrio das } \\
\text { funções imunológicas. }\end{array}$ \\
\hline
\end{tabular}




\begin{tabular}{|c|c|c|c|c|c|}
\hline 19 & $\begin{array}{l}\text { Diet and immune } \\
\text { function }\end{array}$ & $\begin{array}{l}\text { Childs, Calder, } \\
\& \text { Miles (2019) }\end{array}$ & $\begin{array}{l}\text { Revisão da Literatura das } \\
\text { principais funções do } \\
\text { sistema imunológico e } \\
\text { como ele interage com os } \\
\text { nutrientes ao longo da } \\
\text { vida. }\end{array}$ & $\begin{array}{l}\text { Compreender o papel da } \\
\text { dieta e dos nutrientes na } \\
\text { função imunológica; } \\
\text { Facilitar o uso de nutrição } \\
\text { sob medida para melhorar a } \\
\text { saúde humana. }\end{array}$ & $\begin{array}{l}\text { Os nutrientes podem ter um } \\
\text { impacto direto ou indireto sobre } \\
\text { as células imunes, causando } \\
\text { alterações em sua função, ou } \\
\text { podem exercer alterações no } \\
\text { microbioma intestinal. Uma } \\
\text { melhor compreensão do papel } \\
\text { dos nutrientes na função } \\
\text { imunológica facilitará o uso de } \\
\text { nutrição sob medida para } \\
\text { melhorar a saúde humana. }\end{array}$ \\
\hline 20 & $\begin{array}{llr}\text { Skeletal and } & \text { extra- } \\
\text { skeletal actions of } \\
\text { vitamin D: current } \\
\text { evidence } & \text { and } \\
\text { outstanding issues }\end{array}$ & $\begin{array}{l}\text { Bouillon et al., } \\
\text { (2019) }\end{array}$ & $\begin{array}{l}\text { Revisão integrativa a partir } \\
\text { da Avaliação critica de } \\
\text { evidências pré-clínicas e } \\
\text { clínicas do papel da } \\
\text { sinalização da VD em } \\
\text { sistemas fisiológicos, } \\
\text { independente da } \\
\text { homeostase do cálcio. }\end{array}$ & $\begin{array}{l}\text { Pesquisar os benefícios } \\
\text { potenciais bem } \\
\text { documentados da VD e os } \\
\text { riscos associados à } \\
\text { deficiência de VD com o } \\
\text { objetivo de identificar um } \\
\text { status de VD que seja } \\
\text { eficaz e seguro para } \\
\text { proteger a saúde global. }\end{array}$ & $\begin{array}{l}\text { A deficiência de VD aumenta o } \\
\text { PTH sérico, mas a maioria dos } \\
\text { indivíduos com deficiência de } \\
\text { VD não tem concentrações de } \\
\text { PTH acima da faixa normal. Isso } \\
\text { resulta em perda óssea } \\
\text { progressiva e defeitos de } \\
\text { mineralização. } \\
\text { consequências podem ser } \\
\text { evitadas por doses modestas de } \\
\text { suplementos de VD e cálcio. }\end{array}$ \\
\hline 21 & $\begin{array}{l}\text { Vitamin D and its } \\
\text { synthetic analogues }\end{array}$ & $\begin{array}{l}\text { Maestro, Molná } \\
\text { r \& Carlberg } \\
\text { (2019) }\end{array}$ & $\begin{array}{l}\text { Revisão Integrativa a partir } \\
\text { da análise de Análogos da } \\
\text { VD e sua atividade com } \\
\text { receptor VDR "in vitro" e } \\
\text { "in vivo". }\end{array}$ & $\begin{array}{l}\text { Discutir sobre a eficiência } \\
\text { dos análogos da VD e } \\
\text { analisar novas informações } \\
\text { sobre a proteína VDR. }\end{array}$ & $\begin{array}{l}\text { Análogos apresentam alta } \\
\text { atividade com receptor VDR "in } \\
\text { vitro" e com baixos efeitos } \\
\text { calcêmicos "in vivo". Favorecem } \\
\text { o sistema imunológico, porém, } \\
\text { precisam ser mais explorados. }\end{array}$ \\
\hline 22 & $\begin{array}{l}\text { Role of vitamin } D \text { in } \\
\text { preventing infection, } \\
\text { progression and } \\
\text { severity of covid-19 }\end{array}$ & Ali, (2020) & $\begin{array}{l}\text { Revisão Integrativa sobre o } \\
\text { possível papel preventivo } \\
\text { da VD em infecções } \\
\text { agudas } \text { do r trato } \\
\text { respiratório, gravidade e } \\
\text { mortalidade por COVID- } \\
19 .\end{array}$ & $\begin{array}{l}\text { Avaliar a correlação das } \\
\text { concentrações de VD com } \\
\text { casos e mortes de COVID- } \\
19 \text { Evidenciar a } \\
\text { importância do papel da } \\
\text { VD na função } \\
\text { imunológica. }\end{array}$ & $\begin{array}{l}\text { A suplementação de VD têm } \\
\text { efeitos protetores contra } \\
\text { infecções do trato respiratório, } \\
\text { portanto, as pessoas com maior } \\
\text { risco de deficiência de VD } \\
\text { durante esta pandemia global } \\
\text { devem considerar a ingestão de } \\
\text { suplementos de VD para manter } \\
\text { a } 25(\mathrm{OH}) \mathrm{D} \text { circulante nos } \\
\text { níveis ideais }(75-125 \mathrm{nmol} / \mathrm{L}) \text {. }\end{array}$ \\
\hline 23 & $\begin{array}{l}\text { Immunological effects } \\
\text { of vitamin D on human } \\
\text { health and diseases }\end{array}$ & $\begin{array}{c}\text { Charoenngam \& } \\
\text { Holick , (2020) }\end{array}$ & $\begin{array}{l}\text { Revisão Integrativa sobre a } \\
\text { heterogeneidade das } \\
\text { evidências e impacto da } \\
\text { VD na prevenção e } \\
\text { tratamento de doenças } \\
\text { relacionadas ao sistema } \\
\text { imunológico. }\end{array}$ & $\begin{array}{l}\text { Fornecer um resumo de } \\
\text { alto nível dos efeitos } \\
\text { biológicos da VD no } \\
\text { sistema imunológico e a } \\
\text { relação entre a VD e vários } \\
\text { tipos de doenças e } \\
\text { condições relacionadas ao } \\
\text { sistema imunológico; } \\
\text { introduzir o conceito de } \\
\text { responsividade individual à } \\
\text { VD como uma explicação } \\
\text { potencial para tal } \\
\text { heterogeneidade. }\end{array}$ & 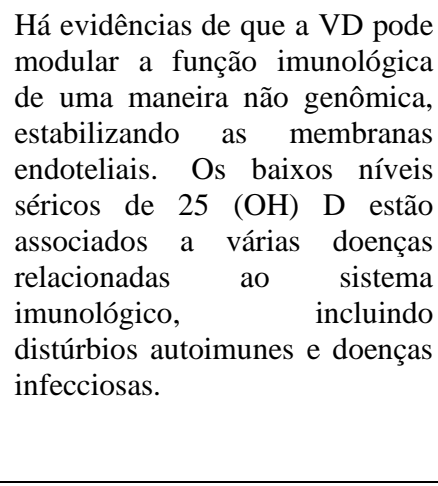 \\
\hline 24 & $\begin{array}{l}\text { Evidence that vitamin } \\
D \text { supplementation may } \\
\text { reduce the risk of } \\
\text { infections and deaths } \\
\text { from influenza and } \\
\text { covid-19 }\end{array}$ & $\begin{array}{l}\text { Grant et al., } \\
\text { (2020) }\end{array}$ & $\begin{array}{l}\text { Revisão Narrativa sobre o } \\
\text { Tratamento de influenza e / } \\
\text { ou COVID-19 com } \\
\text { suplementação de } 25 \\
\text { (OH)D. }\end{array}$ & 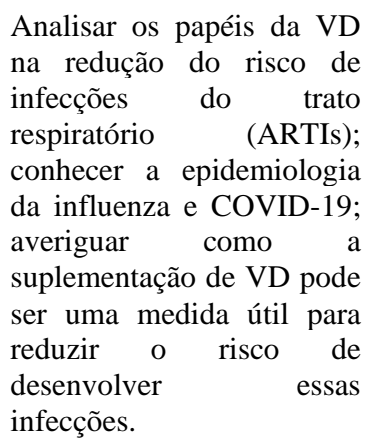 & $\begin{array}{l}\text { Os dados revisados apóiam o } \\
\text { papel de concentrações mais } \\
\text { altas de } 25(\mathrm{OH}) \mathrm{D} \text { na redução } \\
\text { do risco de infecção e morte por } \\
\text { ARTIs (ensaios clínicos } \\
\text { randomizados), incluindo } \\
\text { aquelas de influenza, CoV e } \\
\text { pneumonia. Aconselha-se a } \\
\text { suplementação de VD3 para } \\
\text { elevar as concentrações de } 25 \\
(\mathrm{OH}) \mathrm{D} \text { e prevenir as ARTIs. }\end{array}$ \\
\hline
\end{tabular}




\begin{tabular}{|c|c|c|c|c|c|}
\hline 25 & $\begin{array}{l}\text { The role of vitamin D in } \\
\text { preventing } 2019 \\
\text { coronavirus disease, } \\
\text { infection and mortality }\end{array}$ & $\begin{array}{l}\text { Ilie, Stefanescu } \\
\& \text { Smith }(2020)\end{array}$ & $\begin{array}{l}\text { Meta-análise dos artigos e } \\
\text { informações encontradas } \\
\text { sobre o papel da VD na } \\
\text { prevenção da infecção por } \\
\text { coronavírus. }\end{array}$ & $\begin{array}{l}\text { Propor hipótese de que os } \\
\text { níveis de VD influenciam } \\
\text { na mortalidade por } \\
\text { coronavirus em vários } \\
\text { países. }\end{array}$ & $\begin{array}{l}\text { A VD protege contra infecções } \\
\text { respiratórias, logo, recomenda-se } \\
\text { análise dos níveis de VD em } \\
\text { pacientes com COVID- } 19 .\end{array}$ \\
\hline 26 & $\begin{array}{l}\text { A single large dose of } \\
\text { vitamin D could be used } \\
\text { as a means of } \\
\text { preventing and treating } \\
2019 \quad \text { coronavirus } \\
\text { disease }\end{array}$ & $\begin{array}{l}\text { Liu, Hong \& } \\
\text { Yang (2020) }\end{array}$ & $\begin{array}{l}\text { Revisão Integrativa sobre a } \\
\text { hipótese de que uma única } \\
\text { grande dose de VD poderia } \\
\text { ser uma opção para teste } \\
\text { no COVID19. Estudos } \\
\text { clínicos. }\end{array}$ & $\begin{array}{l}\text { Propor hipótese de que uma } \\
\text { única grande dose de VD } \\
\text { poderia ser uma opção para } \\
\text { teste no COVID-19; } \\
\text { Demonstrar que o baixo } \\
\text { nível de VD está associado } \\
\text { à infecção viral, e que a } \\
\text { suplementação de VD é } \\
\text { benéfica para pessoas } \\
\text { infectadas com vírus. }\end{array}$ & $\begin{array}{l}\text { Com base nos efeitos antivirais e } \\
\text { anticoagulantes da VD, bem } \\
\text { como em sua conveniência e } \\
\text { segurança, especula-se que uma } \\
\text { dose única de } 300.000 \text { UI de VD } \\
\text { pode ser útil para o tratamento } \\
\text { ou prevenção de COVID- } 19 \text {. }\end{array}$ \\
\hline 27 & $\begin{array}{l}\text { Vitamin D3 as potential } \\
\text { treatment adjuvants for } \\
\text { covid-19 }\end{array}$ & $\begin{array}{l}\text { Malaguarnera, } \\
\text { (2020) }\end{array}$ & 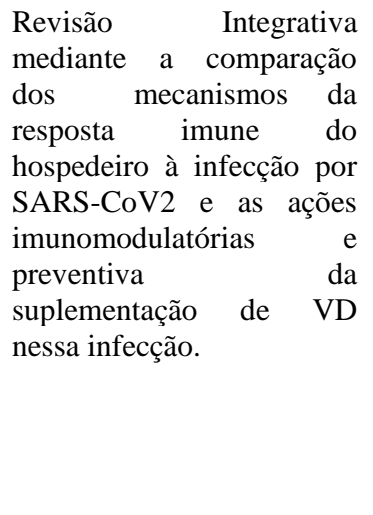 & $\begin{array}{l}\text { Comparar os mecanismos } \\
\text { entre a resposta imune do } \\
\text { hospedeiro à infecção e as } \\
\text { ações imunomoduladoras } \\
\text { da VD; Avaliar se o agente } \\
\text { causador da SARS-CoV2 é } \\
\text { uma infecção que tira } \\
\text { proveito de pacientes com } \\
\text { deficiência de VD, } \\
\text { afetando assim o curso da } \\
\text { doença, e se a } \\
\text { suplementação de VD pode } \\
\text { ser útil para prevenir esta } \\
\text { doença. }\end{array}$ & $\begin{array}{l}\text { Há evidências emergentes que } \\
\text { revelam o papel promissor da } \\
\text { VD na prevenção da tempestade } \\
\text { de co, citocinas } \\
\text { consequentemente, } \\
\text { determinação dos resultados de } \\
\text { SARS-Cov2. Portanto, } \\
\text { tratamento sugerido com } \\
\text { glicocorticóides em combinação } \\
\text { com a suplementação de VD } \\
\text { pode ser uma estratégia } \\
\text { profilática e terapêutica para a } \\
\text { prevenção desta infecção viral. }\end{array}$ \\
\hline 28 & $\begin{array}{l}\text { Evidence of the } \\
\text { protective role of } \\
\text { ultraviolet-B (UVB) } \\
\text { radiation in reducing } \\
\text { deaths from COVID-19 }\end{array}$ & $\begin{array}{l}\text { Moozhipurath, } \\
\text { Kraft \& Skiera } \\
\quad(2020)\end{array}$ & $\begin{array}{l}\text { Revisão Integrativa a partir } \\
\text { de Estudo Observacional } \\
\text { das informações } \\
\text { encontradas sobre o tema. }\end{array}$ & $\begin{array}{l}\text { Analisar a possibilidade } \\
\text { reduzir mortes por COVID- } \\
19 \text { por meio de exposição à } \\
\text { luz solar ou intervenção } \\
\text { com VD. }\end{array}$ & $\begin{array}{l}\text { Embora haja limitações no } \\
\text { estudo, a exposição adequada à } \\
\text { luz solar ou intervenção com } \\
\text { VD se mostrou promissora para } \\
\text { mitigar mortes por COVID-19. }\end{array}$ \\
\hline 29 & $\begin{array}{l}\text { Unraveling the roles of } \\
\text { vitamin D and melanin } \\
\text { status during Covid-19 } \\
\text { (review) }\end{array}$ & $\begin{array}{l}\text { Sidiropoulou et } \\
\text { al., (2020) }\end{array}$ & $\begin{array}{l}\text { Revisão Integrativa sobre } \\
\text { os diversos fatores do } \\
\text { hospedeiro como o status } \\
\text { da VD, pigmentos da } \\
\text { melanina e sua possível } \\
\text { influencia no curso e } \\
\text { resultado do COVID-19. }\end{array}$ & $\begin{array}{l}\text { Explorar as evidências } \\
\text { relacionadas ao status da } \\
\text { vitamina } \mathrm{D} \text { e à } \\
\text { pigmentação da melanina } \\
\text { que podem ter implicações } \\
\text { clínicas no curso e nos } \\
\text { resultados do COVID- } 19 .\end{array}$ & $\begin{array}{l}\text { Em resumo, há evidencias da } \\
\text { correlação do status da VD e dos } \\
\text { polímeros da melanina do } \\
\text { hospedeiro com os resultados } \\
\text { clínicos do COVID-19. } \\
\text { Notavelmente, o conceito de } \\
\text { regulação da VD da tempestade } \\
\text { de citocinas através do RAS abre } \\
\text { novas perspectivas sobre as } \\
\text { funções de sinalização da VD / } \\
\text { VDR, fornecendo uma base para } \\
\text { explorar o uso potencial de } \\
\text { análogos da VD na prevenção } \\
\text { e/ou tratamento de COVID- } 19 .\end{array}$ \\
\hline 30 & $\begin{array}{l}\text { Vitamin D } \\
\text { supplementation during } \\
\text { the covid-19 pandemic }\end{array}$ & $\begin{array}{l}\text { Siuka, Pfeifer \& } \\
\text { Pinter (2020) }\end{array}$ & $\begin{array}{l}\text { Revisão de Literatura sobre } \\
\text { estudos que ressaltam a } \\
\text { relevância } \\
\text { suplementação de VD na } \\
\text { pandemia de covid-19. }\end{array}$ & $\begin{array}{l}\text { Admoestar sobre a } \\
\text { importância } \\
\text { suplementação da VD em } \\
\text { subpopulações com risco } \\
\text { de deficiência de VD e } \\
\text { desfechos desfavoráveis de } \\
\text { COVID-19. }\end{array}$ & $\begin{array}{l}\text { As autoridades de saúde pública } \\
\text { devem reconhecer a importância } \\
\text { e benefícios da suplementação } \\
\text { com VD das subpopulações de } \\
\text { alto risco para resultados } \\
\text { adversos de COVID-19 e } \\
\text { também de indivíduos já } \\
\text { infectados com SARS-CoV-2 a } \\
\text { fim de atingir as concentrações } \\
\text { ideais de } 25(\mathrm{OH}) \text { D3, portanto, } \\
\text { sugere-se que seria razoável } \\
\text { realizar a suplementação dessas } \\
\text { populações. }\end{array}$ \\
\hline
\end{tabular}


Fonte: Autores (2021).

Embora historicamente a VD tenha sido associada à regulação do metabolismo ósseo, essa vitamina também está envolvida em muitos processos biológicos que regulam as respostas imunológicas. Desde a descoberta de receptores VDR em monócitos, células dendríticas e células T ativadas. Estudos "in vitro" mostraram que a VD inibe a atividade pró-inflamatória das células CD4 + Th1 e sua produção de citocinas (Yang et al., 2013).

Segundo Gruber-Bzura (2018), os linfócitos T (células T) incluem alguns tipos de células (chamados subgrupos): células $\mathrm{T} \mathrm{CD}^{+}$, que expressam níveis relativamente elevados de VDR e $1 \alpha$-hidroxilase ativadora da VD. O VDR, também detectado em células imunológicas, sugere que a VD pode regular alguns processos relacionados à imunidade. Foi mostrado "in vitro", que as células T e B humanas ativadas e as células endoteliais que revestem o trato respiratório superior e inferior

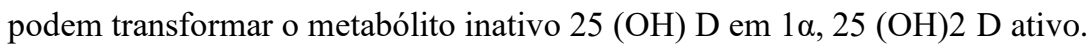

Um estudo epidemiológico em humanos aponta a suplementação com 1,25 (OH)2 D3 como um fator protetor independente que influencia a ocorrência de autoimunidade mediada por Th-1. Os efeitos de 1,25 (OH)2 D no sistema imunológico incluem diminuição das células T CD4 + Th1 / Th17 e citocinas, aumento das células T regulatórias, regulação negativa da produção de IgG conduzida pelas células T e inibição da diferenciação das células dendríticas (Rondanelli et al., 2018).

De acordo com Ali (2020), revisões recentes demonstraram algumas vias pelas quais a VD diminui o risco de infecções microbianas e virais e, consequentemente a mortalidade, por exemplo, para reduzir o risco de resfriado comum, essa vitamina utiliza três mecanismos: barreira física, imunidade celular natural e imunidade adaptativa. Evidenciando o possível papel da VD na redução do risco de infecções e mortalidade por covid-19. Estes compreendem a manutenção de junções celulares e junções gap, aumentando a imunidade celular, diminuindo a tempestade de citocinas com influência no interferon $\gamma$ e fator de necrose tumoral $\alpha$ regulando a imunidade adaptativa através da inibição das respostas das células T helper tipo 1 e da estimulação da indução das células $\mathrm{T}$.

Gois et al.(2017), destacam que numerosos estudos embasam o papel da VD nas respostas imunes inatas e adaptativas após infecções virais e bacterianas, ademais, várias células do sistema imunológico expressam o receptor VD (VDR) e respondem diretamente a $1,25(\mathrm{OH}) 2 \mathrm{VD}$.

O receptor da VD (VDR) é um receptor nuclear que pode afetar diretamente a expressão gênica e encontra-se presente na maioria das células imunes, o que denota a relevância deste micronutriente nas atividades das células imunes. Além disso, a enzima 1- $\alpha$-hidroxilase de ativação da VD (CYP27B1), que resulta no metabólito ativo $1 \alpha$, 25-dihidroxivitamina D3 (1,25 (OH)2 D3 ), é expressa em muitos tipos de células imunológicas. A ligação de VDR por 1,25 (OH)2 D3 pode incentivar a produção de proteínas antimicrobianas e interferir na produção de citocinas pelas células imunes, evidenciando a importância do papel da VD no sistema imunológico (Childs, Calder, \& Miles, 2019).

Segundo Maestro, Molnár \& Carlberg (2019), o VDR, é a única proteína expressa pelo genoma humano que tem a capacidade de ligar-se a 1,25 (OH)2 D3 e a seus análogos em concentrações subnanomolares. Sendo assim, todas as funções fisiológicas dos compostos da VD são mediadas pelo VDR e seus genes-alvo. O gene VDR é expresso de forma mais elevada no intestino, rins e ossos, todavia, é expresso em menor quantidade em outros tecidos e células humanas, comprovando sua relação também com as células imunológicas.

É válido ressaltar que além das funções endócrinas, a VD também atua de forma parácrina ou autócrina em ambiente imunológico. Algumas das ações não clássicas mais recentemente reconhecidas da VD incluem efeitos sobre a proliferação e diferenciação celular e efeitos imunológicos que resultam na capacidade de manter a tolerância e promoção da imunidade protetora (Aranow, 2011). 
A exposição à VD leva a uma mudança de um estado imunológico pró-inflamatório para um mais tolerogênico, incluindo diversos efeitos nos subtipos de células T: $\mathrm{O}$ calcitriol suprime a proliferação, diferenciação das células $\mathrm{T}$ auxiliares (Th) e modula sua produção de citocinas. Em particular, o tratamento de células T com calcitriol ou análogos inibe a secreção de citocinas pró-inflamatórias Th1 (IL2, interferon- $\gamma$, fator de necrose tumoral $\alpha$ ), Th9 (IL9) e Th22 (IL22) e promove a produção de citocinas Th2 antiinflamatórias (IL3, IL4, IL5, IL10), as células Th17 produtoras de IL17 também são afetadas pela VD (Prietl et al., 2013).

A 25(OH)D3 suprime a imunidade adaptativa, regulando negativamente as respostas imunes mediadas por células $\mathrm{T}$ helper (Th) 1, inibindo a produção de citocinas pró-inflamatórias como Interferon- $\gamma$ (IFN- $\gamma$ ), IL-6, IL-2 e TNF- $\alpha$ e a produção de citocinas inflamatórias em diferentes doenças. Essa vitamina é um conhecido regulador da imunidade inata, os primeiros dados sobre o assunto foram gerados no tratamento de doenças causadas por micobactérias, como tuberculose e hanseníase. A 1,25 (OH)2 D3 aumenta a produção de defensina $\beta 2$ e peptídeo antimicrobiano catelicidina (CAMP) por macrófagos e queratinócitos monócitos aumentando sua atividade antimicrobiana (Sassi, Tamone \& D'Amelio, 2018).

Sidiropoulou et al. (2020), destacam que a VD ajuda a preservar a integridade da junção intercelular epitelial, melhorando a defesa da mucosa do hospedeiro contra a invasão de patógenos. A um nível celular, metabolitos da VD modulam respostas antivirais inatas, em parte, por meio da regulação de peptídeos antimicrobianos, tais como catelicidina humana e defensinas, para promover autofagia. Já os efeitos imunes adaptativos da VD incluem a inibição de células T CD $4{ }^{+}$Th1/Th17 e citocinas, como TNF- $\alpha$ e IFN- $\gamma$, juntamente com ações estimuladoras em Th2 e células T regulatórias (Tregs). Ao regular negativamente a sinalização pró-inflamatória precoce em favor de um perfil Th2/Treg antiinflamatório, a 1,25 $(\mathrm{OH}) 2 \mathrm{D} 3$ pode suprimir o meio de citocinas alterado por estímulos virais e bacterianos, conforme observado em pacientes com COVID-19, reduzindo assim o risco de danos extensos nos tecidos devido à inflamação descontrolada.

Segundo Malaguarnera (2020), a síndrome do desconforto respiratório agudo (SDRA), caracterizada por comprometimento endotelial e aumento da permeabilidade da barreira, é a principal causa de morbidade e mortalidade em pacientes com SARS-CoV-2 grave. As células epiteliais alveolares tipo II expressam ACE2 (AECII) que auxiliam na replicação viral corona. Um dos mecanismos mediados pela VD pode evitar a lesão pulmonar aguda por meio da inibição da expressão de renina, ACE e Angiotensina II, provocando a indução da atividade do eixo ACE2 / Ang- (1-7), inibindo a renina e a cascata Enzima conversora de angiotensina (ACE)/Angiotensina II(Ang II)/receptor de angiotensina (AT $\left.{ }_{1} \mathrm{R}\right)$. Dessa forma, a VD previne vasoconstrição, inflamação, proliferação celular, fibrose, estresse oxidativo e ativa a autofagia.

Nair, Venkatesh e Center (2018), ressaltam que um estudo observacional em pacientes gravemente enfermos demonstrou uma associação entre deficiência/insuficiência de VD e resultados adversos, como por exemplo, maiores escores de gravidade da doença e risco de morte, maior permanência na UTI, maior duração da ventilação mecânica, aumento das taxas de pneumonia associada à ventilação, positividade da hemocultura e um aumento da incidência de disfunção orgânica, entre outros, o que demanda maiores custos hospitalares, essa deficiência de VD pode servir como preditor de resultados negativos, sendo particularmente importante em doenças críticas, como COVID-19.

Liu, Hong e Yang (2020), reforçam que tanto a disfunção imunológica quanto a tempestade de citocinas desempenham um papel fundamental no desenvolvimento da COVID-19, doença respiratória aguda, cuja morbidade e mortalidade está associada à coagulopatia significativa, que leva à trombose, causando falência de múltiplos sistemas ou órgãos. Sabe-se que a VD modula a função de células imunes, como células T e B, monócitos e células dendríticas, em uma interação entre o sistema imune inato e adaptativo, e regula a expressão e secreção de citocinas como TNF e IL-6. Dessa forma, a deficiência ou insuficiência de VD pode ser um contribuinte implícito para a coagulopatia associada a COVID-19, visto que, essa vitamina pode desempenhar um papel anticoagulante por meio da melhora do nível de fibrinogênio sérico e do 
tempo de tromboplastina parcial ativada, podendo ser utilizada no tratamento desses pacientes para prevenir que casos leves se tornem graves.

O vírus SARS-CoV-2 adentra ao epitélio respiratório por meio de receptores de entrada específicos, onde causam danos celulares e teciduais e disparam respostas imunes inatas e adaptativas, que resultam em inflamação das vias aéreas e sistêmicas e, em casos graves, sepse com risco de vida ou síndrome do desconforto respiratório agudo. A 1,25 (OH)2 D exerce atividades antivirais e modula a resposta inflamatória à infecção viral, estimulando a liberação de catelicidina, modulação da expressão do receptor toll-like e função das células NK, suprimindo a superexpressão de citocinas pró-inflamatórias, portanto, a suplementação de VD2 ou D3 pode proteger contra o desenvolvimento e gravidade da infecção por COVID-19 (Charoenngam \& Holick, 2020).

Ilie, Stefanescu e Smith (2020), enfatizam que, já foi demonstrado que a VD protege contra infecções respiratórias agudas e seu uso é considerado seguro, no entanto, é aconselhável realizar estudos sobre os níveis de VD em pacientes com COVID-19 com diferentes graus de gravidade da doença.

Rosen et al. (2012), salientam que, o VDR é amplamente distribuído por diferentes tecidos do corpo, muitos desses tecidos não eram originalmente considerados alvos para 1,25- $(\mathrm{OH}) 2 \mathrm{D}$. A descoberta de VDR em muitos tipos de células, juntamente com a demonstração de que 1,25- $(\mathrm{OH}) 2 \mathrm{D}$ altera acentuadamente a função desses tecidos, fez aumentar o interesse nos efeitos multiformes de 1,25- $(\mathrm{OH}) 2 \mathrm{D}$.

A reposição de VD melhora a imunidade inata (a resposta imediata dos macrófagos aos vírus e bactérias invasores nas membranas mucosas), reduzindo a incidência e a gravidade das infecções respiratórias agudas. Este efeito requer um nível sérico suficiente de $25(\mathrm{OH})$ D3 sendo crucial para os macrófagos ativá-lo no hormônio D (calcitriol), que ativa genes para a síntese de fatores antimicrobianos destruidores de vírus (como SARS-CoV-2), fungos e bactérias, modulando a resposta imune celular e atenuando a tempestade de citocinas (Siuka, Pfeifer, Pinter \& 2020).

A deficiência de VD aumenta a probabilidade de resposta imunológica enfraquecida, doenças infecciosas no trato respiratório superior, aumento da gravidade e mortalidade em pacientes enfermos. A VD, por meio de sua forma ativa, 1,25dihidroxivitamina $\mathrm{D}$ [1,25 (OH)2 D], aumenta a imunidade inata pelo estimulo de peptídeos antimicrobianos, como defensinas e catelicidina humana, com efeitos antivirais, capaz de interromper os envelopes virais, modula a resposta inflamatória suprimindo a expressão excessiva de citocinas pró-inflamatórias, reduzindo assim o risco de tempestade de citocinas, desempenhando um papel essencial na imunomodulação de ambos os sistemas imunes inato e adaptativo, podendo reduzir biologicamente o risco de casos graves e mortes por COVID-19 (Moozhipurath et al., 2020).

Grant et al.(2020), destacam que a VD também aumenta a imunidade celular, em parte reduzindo a tempestade de citocinas induzida pelo sistema imunológico inato, responsável por gerar citocinas pró-inflamatórias e anti-inflamatórias em resposta a infecções virais e bacterianas, conforme observado em pacientes com COVID-19. A VD pode reduzir a produção de citocinas Th1 pró-inflamatórias, como o fator de necrose tumoral $\alpha$ e o interferon $\gamma$. A administração de VD reduz a expressão de citocinas pró-inflamatórias e aumenta a expressão de citocinas antiinflamatórias por macrófagos.

Bouillon et al. (2019), ressaltam que os efeitos esqueléticos da deficiência moderada de VD em adultos ou idosos são causados principalmente por um aumento da concentração sérica de paratormônio, levando a uma alta reabsorção óssea e à perda óssea cortical associada. Em se tratando de efeitos extra-esqueléticos, um baixo nível de VD está relacionado à obesidade e ao diabetes tipo 2 em humanos, fatores de risco para a COVID-19.

Quanto aos níveis de $25(\mathrm{OH})$ D, estes são tipicamente mais baixos em indivíduos obesos que têm maior probabilidade de desenvolver diabetes mellitus e síndrome metabólica. Os adipócitos expressam o VDR, e 1,25 (OH)2 D promove aumento da lipogênese e diminuição da lipólise (Bikle, 2014). 
Segundo Gallagher (2013), o envelhecimento reduz a produção de VD na pele, pois há uma diminuição da concentração de 7-desidrocolesterol na epiderme em idosos em comparação com os jovens e uma resposta reduzida à luz ultravioleta, resultando em uma diminuição de $50 \%$ na formação da pré-vitamina D3. Todas as mudanças relacionadas à idade no metabolismo da VD são ampliadas quando há deficiência de VD simultaneamente, porque ela limita o suprimento de substrato para 25OHD e, finalmente, 1,25 (OH) 2 D. Dessa forma ocorre diminuição da absorção de cálcio, resistência intestinal à absorção para $1,25(\mathrm{OH}) 2 \mathrm{D}$, Circulante, VDR diminuído, diminuição da produção de 1,25(OH)2 $\mathrm{D}$ pelo envelhecimento do rim, diminuição da produção de VD na pele, deficiência de substrato de VD. A deficiência de substrato é um problema comum em idosos e mulheres gestantes, por isso é importante reconhecer porque pode ser evitada e tratada (Dutra et al, 2020)

Uma fonte importante a ser citada é a radiação UVB, que está diretamente relacionada a intensidade da luz solar, variações sazonais e latitude, ou seja, quanto mais longe da linha do equador, menos época solar se tem, logo, as concentrações de VD são diretamente dependentes da dose de radiação UVB ultravioleta, portanto, as concentrações de VD tendem a ser mais baixas durante a temporada de inverno e para graus mais elevados de latitude. Outros fatores que influenciam os níveis de absorção de VD são: o índice de massa corporal (IMC), fatores genéticos, dieta e etnia, pois a melanina reduz a absorção, todavia, não a bloqueia, por isso, pessoas de tons de pele mais claras necessitam de doses mais baixas de radiação enquanto que pessoas de tons mais escuros necessitam de doses mais altas de radiação para produzir o hormônio D (Ferrari, Lombardi, \& Banfi, 2017).

De acordo com Christakos et al., (2015), a deficiência grave de VD em crianças, deve-se à falta de exposição à luz solar e à baixa ingestão de VD, sendo endêmica em várias áreas do mundo. Já no envelhecimento, conforme indicado em estudos em animais e humanos, há um declínio na capacidade do rim de sintetizar 1,25 (OH)2 D3.

Para Biondi et al., (2017), a deficiência de VD é uma condição muito comum em idosos e adultos jovens, com muitas consequências clínicas, principalmente em relação ao papel do hormônio na regulação do metabolismo esquelético e do cálcio e em muitos outros sistemas. As evidências disponíveis indicam que os níveis séricos de 25 (OH) D> $30 \mathrm{ng} / \mathrm{mL}$ (75 nmol/L) são desejáveis para a manutenção da saúde dos indivíduos. Sua deficiência está associada ao aumento do risco de muitas condições crônicas.

Charoenngam e Holick (2020), destacam que o aumento da pandemia de COVID-19, a taxa desproporcional de infecção sintomática, morbidade e mortalidade observada são maiores em pessoas negras e obesas, isso sugere o possível impacto da VD na resposta do hospedeiro e suscetibilidade à infecção nestes indivíduos por apresentarem um risco elevado de deficiência de VD. Além dos efeitos imunomoduladores e antivirais, a 1,25 $(\mathrm{OH}) 2 \mathrm{D}$ atua especificamente como um modulador da via renina-angiotensina e regula negativamente a expressão da expressão da enzima conversora de angiotensina2, que serve como o receptor da célula hospedeira que medeia a infecção por SARS-CoV-2. Isso denota que a suplementação de VD pode reduzir o risco e a gravidade da infecção por COVID-19.

Sobre a toxicidade da VD, ainda não bem definida na literatura, vários laboratórios comerciais de referência têm valores de corte variáveis para o limite superior do normal para os níveis de 25-hidroxivitamina D [25 (OH) D]. Diversas literaturas definem que a toxicidade ocorre a partir de níveis superiores a $80 \mathrm{ng} / \mathrm{mL}$, outras sugerem que ela acontece com níveis que excedam $120 \mathrm{ng} / \mathrm{mL}$. Pacientes que tomam altas concentrações de doses e suplementação líquida apresentam risco aumentado de níveis mais elevados de $25(\mathrm{OH}) \mathrm{D}$, isso denota que o risco de alguém ter uma overdose ou tomar a quantidade incorreta com tais doses concentradas é insólito (Lee et al., 2018).

A exposição ao sol desprotegida é a principal fonte de VD e na sua ausência, é difícil obter a quantidade adequada a partir de fontes dietéticas sem suplementação para satisfazer as necessidades do corpo. Concernente à prática clínica de suplementação da VD, as organizações e autoridades de saúde recomendam diferentes RDAs (Recommended Dietary 
Allowances) em sua diretriz de prática clínica sobre avaliação, tratamento e prevenção da deficiência de VD, a Endocrine Society sugere diferentes níveis séricos de 25(OH)D (Holick, Binkley \& Bischoff-Ferrari, 2011). No Quadro 3 são demonstrados os níveis séricos da VD e faixa etária.

Quadro 3: Níveis séricos da VD.

\begin{tabular}{|c|c|}
\hline Faixa etária & $\begin{array}{c}\text { Nível sérico 25(OH)D de } 30 \mathrm{ng} / \mathrm{ml} \text { para manutenção da Função óssea e } \\
\text { muscular (dose diária) }\end{array}$ \\
\hline Crianças 0-1 ano & 400-UI (25ng/ml) \\
\hline Crianças mais velhas & 600-UI \\
\hline Adultos 19-50 anos & 600-UI \\
\hline Adultos $>50$ anos & 600-UI \\
\hline Adultos $>70$ anos & 800-1000-UI \\
\hline $\begin{array}{l}\text { Obs.: Mulheres grávidas ou } \\
\text { amamentando. }\end{array}$ & 600-UI \\
\hline
\end{tabular}

Fonte: Endocrine Society, (2011).

Ainda de acordo com Holick, Binkley e Bischoff-Ferrari (2011), o Subcomitê de Diretrizes Clínicas da Endocrine Society considera a deficiência de VD uma área prioritária que necessita de diretrizes práticas com formulações e recomendações baseadas em evidências que podem facilitar a prática clínica e tornar acessível muitos dos benefícios pleiotrópicos à saúde relacionados à VD.

Embora a terapia com VD seja considerada segura, com estudos revelando que doses de longo prazo de até 10.000 UI diárias não estão associadas à toxicidade, o uso de preparações de VD fabricadas erroneamente e rotuladas de forma incorreta expõe os pacientes ao risco de toxicidade, da mesma forma, o uso de uma dose menor do que a indicada, não valorizada, pode resultar em tratamento ineficaz, colocando o paciente em risco de sintomas persistentes ou mesmo submetendo-o a investigação desnecessária por suspeita de má absorção (Davies, Poole \& Feldschreiber, 2014).

Portanto, mais atenção deve ser dada à deficiência de VD na prática médica e farmacêutica, uma vez que vários estudos confirmam o papel essencial da vitamina do sol em uma variedade de funções fisiológicas e preventivas. Os resultados desses estudos são consistentes com a recomendação de melhorar o estado geral de VD em crianças e adultos por meio de uma abordagem saudável à exposição solar, consumo de alimentos que contenham VD e suplementação com preparações de VD devidamente monitoradas por profissionais de saúde (Gröber, Reichrath \& Holick, 2015).

\section{Conclusão}

Em suma, é vasta a literatura que avalia a relação da adequação da VD com as doenças humanas, inclusive com a infecção por coronavírus. Essa vitamina desempenha várias funções no organismo, possivelmente por causa da presença do VDR na maioria das células humanas não esqueléticas, por meio de vários processos biológicos regula as respostas imunológicas, acentua a imunidade celular, em parte reduzindo a tempestade de citocinas induzida pelo sistema imunológico inato, reduz citocinas pró-inflamatórias e aumenta a resposta anti-inflamatória em infecções virais e bacterianas.

As células do sistema imunológico são capazes de sintetizar e responder à VD, podendo ser útil no tratamento preventivo e adjuvante do COVID-19. No entanto, diversos fatores influenciam os níveis séricos dessa vitamina no organismo, tais como: variações sazonais, latitude, índice de massa corporal (IMC), fatores genéticos, idade, dieta e etnia.

Desse modo, a suplementação seria a ferramenta terapêutica efetiva para contrapor a deficiência de VD, para isso, estratégias de assistência e atenção farmacêutica são necessárias para monitorar seu uso. Portanto, são necessários estudos mais 
aprofundados sobre o coronavírus e a suplementação de $\mathrm{VD}$, bem como a atuação dessa vitamina frente às novas cepas do COVID-19.

\section{Referências}

Ali, N. (2020) Papel da vitamina D na prevenção da infecção, progressão e gravidade da covid-19. J Infect Public Health. 13 (10): $1373-1380$.

Aranow, C. (2011) Vitamina D e o sistema imunológico. J Investig Me. 59:881-886

Bardin, L. (2011). Análise de conteúdo. Edições 70. 820 p.

Bikle, D. D. (2014) Metabolismo da vitamina D, mecanismo de ação e aplicações clínicas. Chem Biol. 21 (3): 319-329.

Biondi P., Pepe J., Biamonte F., Occhiuto M., Parisi M., Demofonti C., Baffa V., Minisola S., \& Cipriani C. (2017) O calcidiol oral é uma boa forma de suplementação de Vitamina D. Clin Cases Miner Bone Metab. 14 (2): 207-208.

Bouillon, R., et al (2019) Skeletal and extraskeletal. Ações esqueléticas e extra-esqueléticas da vitamina D: evidências atuais e questões pendentes. Endocr. Rev. 2019; 40: 1109-1151

Chan, J. F., et al (2020). Caracterização genômica do novo coronavírus patogênico humano de 2019 isolado de um paciente com pneumonia atípica após visitar Wuhan. Emerg Microbes Infect. 2020; 9 : 221-236.

Charoenngam, N., \& Holick M. F. (2020) Efeitos imunológicos da vitamina D na saúde e nas doenças humanas. Nutrientes. 12 (7): 2097.

Childs, E. C., Calder, C. P. \& Miles, A. E. (2019) Dieta e função imunológica. Nutrientes. 11 (8): 1933

Christakos, S., et al. (2016) Vitamina D: Metabolismo, mecanismo molecular de ação e efeitos pleiotrópicos. Physiol Rev. 96 (1): $365-408$

Coronavírus covid-19. (2020) Formas de Transmissão. https://coronavirus.es.gov.br/.

Davies, J. S., Poole, C. D. \& Feldschreiber, P (2014). Os aspectos médico-legais da prescrição de vitamina D. Br J Clin Pharmacol. 78 (6): $1257-63$

Dutra, J. M., Brito, I. G., Maia, G. P. A. G., Faria, A. B., Chagas, P. P. \& Plácido, G. R. (2020). Deficiência e biodisponibilidade da vitamina D: Uma revisão bibliográfica. Research, Society and Development, 9(7), e23973555

Ferrari, D., Lombardi, G. \& Banfi, G. (2017) Em relação ao intervalo de referência da vitamina D: variabilidade pré-analítica e analítica da medição da vitamina D. Med (Zagreb) 27 (3): 030501

Folha Informativa COVID-19-Escritório da OPAS e da OMS no Brasil (2011) https://www.paho.org/pt/covid19

Gallagher, J. C. (2013) Vitamina D e envelhecimento. Endocrinol Metab Clin North. 42 (2): 319-32.

Gois, P. H. F., Ferreira D., Olenski S. B \& Seguro, A. C. (2017) Vitamina D e doenças infecciosas: Simples observador ou fator contribuinte? Nutrientes. 9 (7): 651

Grant, W. B., et al (2020) Evidência de que a suplementação com vitamina D pode reduzir o risco de infecções e mortes por influenza e COVID19. Nutrientes. 2020; 12 : 988

Gröber U., Reichrath J. \& Holick M. F. (2015) Viva mais tempo com vitamina D? Nutrientes. 7 (3): 1871-80.

Gruber-Bzura, B. M. (2018) Vitamina D e Prevenção ou Terapia da Gripe? Int. J. Mol. Sci. 2018; $19: 2419$

Holick M. F., Binkley N. C. \& Bischoff-Ferrari, H. A. (2011) Avaliação da Endocrine Society, tratamento e prevenção da deficiência de vitamina D: uma diretriz de prática clínica da Endocrine Society. J Clin Endocrinol Metab 96 (7): 1911-1930

Ilie, P. C., Stefanescu, S., \& Smith L. (2020). O papel da vitamina D na prevenção da doença coronavírus 2019, Infecção e Mortalidade. Aging Clin Exp Res. 32 (7): 1195-1198

Lee J.P., Tansey M., Jetton, J. G. \& Krasowski, M. D. (2018). Toxicidade da Vitamina D: um estudo retrospectivo de 16 anos em um Centro Médico Acadêmico. Lab. Med. 2018; 49: 123-129

Liu, G., Hong T. \&Yang, J. (2020) Uma única dose grande de vitamina D poderia ser usada como um meio de prevenção e tratamento da doença coronavírus 2019. Droga Des Devel Ther. 14: 3429-3434.

Maestro M. A., Molnár F. \& Carlberg C. (2019) Vitamina D e seus análogos sintéticos. J Med Chem. 62 (15): 6854-6875

Malaguarnera, L. (2020). Vitamina D3 como adjuvantes potenciais de tratamento para COVID-19. Nutrientes.12 (11): 3512.

Moozhipurath R. K., Kraft L., \& Skiera B. (2020). Evidência do papel protetor da radiação ultravioleta B (UVB) na redução de mortes por covid-19. Sci Rep. 10 (1): 17705

Nair P., Venkatesh, B. \& Center, J. R. (2018). Deficiência de vitamina D e suplementação em doenças críticas - os conhecidos e desconhecidos conhecidos. Crit Care. 22(1): 276. 
Research, Society and Development, v. 10, n. 7, e20510716296, 2021

(CC BY 4.0) | ISSN 2525-3409 | DOI: http://dx.doi.org/10.33448/rsd-v10i7.16296

Prietl, B., Treiber, G., Pieber, T. R. \& Amrein, K. (2013). Vitamina D e função imunológica. Nutrientes. 2013; 5: 2502-2521.

Rawat, K., Kumari, P \& Saha, L. (2021) . Covid-19 vacina: uma atualização recente no gasoduto vacinas, suas estratégias de design e desenvolvimento. Eur J Pharmacol. 5 892: 173751

Rondanelli M., Miccono A., Lamburghini S., Avanzato I., Riva A., Allegrini P (2018). Autocuidado para resfriados comuns: o papel central da vitamina D, vitamina $\mathrm{C}$, zinco e equinácea em três sistemas imunológicos principais grupos interativos (barreiras físicas, imunidade inata e adaptativa) envolvidos durante um episódio de resfriados comuns - conselhos práticos sobre dosagens e na hora de tomar esses nutrientes / botânicos para prevenir ou tratar resfriados comuns. Evid Based Complement Alternat Med. 2018: 5813095

Rosen C. J., Adams J. S., Bikle D. D., Black D. M., Demay M. B., Manson J. E., Murad M. H., \& Kovacs C. S. (2012) Os efeitos não-esqueléticos da vitamina D: Uma declaração científica da sociedade endócrina. Endocr. Ver. 33 : 456-492

Sassi F, Tamone C., \& D'Amelio P. (2018). Vitamina D: nutriente, hormônio e imunomodulador. Nutrientes. 10 (11): 1656.

Sidiropoulou, P, et al. (2021). Desvendando os papéis do status da vitamina D e da melanina durante covid-19 (revisão). Int J Mol Med. 47 (1): $92-100$

Siuka D., Pfeifer M., \& Pinter B. (2020). Suplementação com vitamina D durante a pandemia de COVID-19. Mayo Clin Proc. 95 (8): 1804-1805

Souza M. T. De, Silva M. D. Da \& Carvalho R. (2010) Revisão Integrativa: o que é e como fazer. Einstein (São Paulo) 8(1).

Yang C. Y., Leung P. S., Adamopoulos I. E. \& Gershwin M.E . (2013) A implicação da vitamina D e autoimunidade: uma revisão abrangente. Clin Rev Allergy Immunol. 45 (2): 217-26. 